\section{Characterization and Identification of the Main Spanish and Italian Olive Cultivars by Simple-sequence-repeat Markers}

\author{
A. Belaj ${ }^{1}$ \\ Departamento de Agronomía, ETSIAM, Universidad de Córdoba, Avenida \\ Ménendez Pídal s/n, Apdo 3048, 14080 Córdoba, Spain
}

G. Cipriani and R. Testolin

Dipartimento di Produzione Vegetale e Tecnologie Agrarie, Universita degli Studi di Udine, Via delle Scienze 208, 33100 Udine, Italy

\section{Rallo and I. Trujillo}

Departamento de Agronomía, ETSIAM, Universidad de Córdoba, Avenida Ménendez Pídal s/n, Apdo 3048, 14080 Córdoba, Spain

Additional index words. Olea Europaea, DNA markers, DNA fingerprinting, microsatellites

\begin{abstract}
Nine simple-sequence-repeat (SSR) primer pairs were assayed in 35 Spanish and Italian olive cultivars of commercial interest. All microsatellites were polymorphic, showing 5 to 13 alleles per locus ( 7.5 alleles per locus on average). The frequency of each alleles was generally low, with most of the alleles present at one or two cultivars. Heterozigosity ranged from 0.15 to 0.95 ; the discrimination power (PD) ranged from 0.30 to 0.93 (mean 0.79 ). The set of microsatellites analyzed discriminated all cultivars investigated. The combination of only three SSR primer pairs-UDO99-009+UD099-043+UDO99-14-made possible the identification of all cultivars included in the study. Cluster analysis did not find differences between Spanish and Italian cultivars, but most of the cultivars from southern and central Spain grouped together. Hence, microsatellites markers are recommended for olive fingerprinting to generate a database for olive cultivar identification.
\end{abstract}

Olive (Olea europaea L.) is a species of great economic importance in the Mediterranean basin, where $95 \%$ of world production is concentrated. Among Mediterranean countries, Spain and Italy occupy a very important place in the olive industry. Spain is the leading olive producing country, while Italy is the main exporter of olive oil in the world. The genetic patrimony of both these countries is very rich and is characterized by the abundance of cultivars, most of them landraces vegetatively propagated at the farm level since ancient times (Barranco, 1997; Cimato et al., 1993).

The existence of many varieties maintained by vegetative propagation reinforces the need of a reliable identification of cultivars, for nurserymen and growers benefit as plant cost represents the major investment in the new orchards. At the moment, the world olive industry is expanding and being revived in many countries situated outside the confines of the

Received for publication 1 Nov. 2002. Accepted for publication 1 Aug. 2004. Contribution from the Department of Agronomy, University of Cordoba, Cordoba, Spain. We are thankful to the World Olive Germplasm Bank of CIFA Alameda del Obispoin Cordoba, (Spain) and to the Dipartimento di Produzione Vegetale e Tecnologie Agrarie, of the University of Udine (Italy) for all the facilities created to accomplish this work. Special thanks are due to L. Zulini for the excellent technical assistance in the laboratory and to T. Marrazzo and G. di Gaspero for their help at SSRs analyses of data.

'E-mail ag2belay@uco.es.
Mediterranean (Mekuria et al., 1999; Wiesman et al., 1998). The main cultivars of the Mediterranean area, together with local forms, are being propagated there. Furthermore, most olive collections in the world (Bartolini et al., 1998) include foreign cultivars from Greece, Israel, Italy, Spain, and other countries. It is thus necessary to identify cultivars that are recognized worldwide to ensure the quality of products according to internationalstandards.

Classical approaches for identifying olive cultivars have been based on morphology (Barranco and Rallo 1984; 2000; Cantini et of origin. al., 1999; Cimato et al., 1993; Prevost et al., 1993; Tous and Romero, 1993). Although these markers provide a very useful tool for identification, they have limitations because of environmental influences, the need for extensive observations of mature plants, and the requirment of a very well-trained staff (Belaj et al., 2001).

The development of molecular techniques has made possible the use of other genetic markers such as isoenzymes (Patumi et al., 1994; Trujillo et al., 1995), RAPDs (Belaj et al., 2001; Fabbri et al., 1995; Sanz-Cortés et al., 2001; Vergari et al., 1996), and AFLPs (Baldoni et al., 2000) for the study of olive germplasm of these countries.

Microsatellite markers hold great promise for developing a reliable and routine method for identification of olive cultivar genetic diversity as well as mapping and gene tagging purposes (Cipriani et al. 2002). Microsatellites are useful because they are abundant, uniformly distributed, highly polymorphic, codominant, rapidly produced by PCR, and relatively simple to interpret (Rafalski et al., 1996). Furthermore, they are highly reproducible within and between laboratories. More than 60 primer pairs are now available in olive (Carriero et al., 2002; Cipriani et al., 2002; de la Rosa et al., 2002; Rallo et al., 2000; Sefc et al., 2000), and many more are expected to be produced.

The screening of microsatellite alleles in important varieties would generate a database for variety identification and breeding programs. This paper reports on the microsatellite polymorphism observed among Spanish and Italian olive cultivars of commercial interest and their value for cultivar identification as well as for variability studies.

\section{Material and Methods}

Plant material. Thirty-five olive cultivars, chosen on the basis of their wide diffusion in Spain and Italy, were included in the study (Table 1). All samples were obtained from the World Olive Germplasm Bank of the Centro de Investigación y Formación Agraria (CIFA) Alameda del Obispo in Cordoba, (Spain),

Table 1. Olive cultivars analyzed, including their register number (RN), in the collection and the country

\begin{tabular}{lrllrc}
\hline Cultivar & RN & Origin & Cultivar & RN & Origin \\
\hline 'Alfafara' & 605 & Spain & 'Leccino' & 82 & Italy \\
'Aloreña' & 829 & Spain & 'Leccio del Corno' & 83 & Italy \\
'Arbequina' & 231 & Spain & 'Lechín de Granada' & 54 & Spain \\
'Ascolana Tenera' & 62 & Italy & 'Lechín de Sevilla' & 5 & Spain \\
'Bical' & 387 & Spain & 'Manzanilla Cacereña' & 430 & Spain \\
'Blanqueta' & 11 & Spain & 'Manzanilla Sevillana' & 21 & Spain \\
'Carolea' & 736 & Italy & 'Moraiolo' & 78 & Italy \\
'Castellana' & 576 & Spain & 'Morisca' & 17 & Spain \\
'Cellina' & 179 & Italy & 'Morrut' & 224 & Spain \\
'Changlot Real' & 15 & Spain & 'Picual' & 9 & Spain \\
'Cornicabra' & 10 & Spain & 'Picudo' & 3 & Spain \\
'Coratina' & 79 & Italy & 'Rosciola' & 227 & Italy \\
'Empeltre' & 13 & Spain & 'Sevillenca' & 988 & Spain \\
'Farga' & 12 & Spain & 'Verdial de Badajoz' & 6 & Spain \\
'Frantoio' & 80 & Italy & 'Verdial de Huevar' & Spain \\
'Gordal Sevillana' & 234 & Spain & 'Verdial de Velez-Málaga' & 883 & Spain \\
'Hojiblanca' & 2 & Spain & 'Villalonga' & 364 & Spain \\
'Itrana' & 68 & Italy & & & \\
\hline
\end{tabular}


Table 2. Number of alleles, size range, gene diversity $(\mathrm{H})$, and power of discrimination (PD) of 9 microsatellite loci screened in 35 Spanish and Italian olive cultivars.

\begin{tabular}{lcccc}
\hline Locus & No. of alleles & Size range & H & PD \\
\hline UDO99-008 & 5 & $160-171$ & 0.73 & 0.75 \\
UDO99-009 & 8 & $83-119$ & --- & 0.90 \\
UDO99-011 z & 9 & $106-132$ & -- & 0.90 \\
UDO99-014 & 6 & $95-126$ & --- & 0.88 \\
UDO99-019 & 5 & $103-169$ & 0.15 & 0.30 \\
UDO99-024 & 8 & $168-202$ & 0.65 & 0.82 \\
UDO99-031 & 8 & $113-155$ & 0.78 & 0.90 \\
UDO99-039 & 7 & $167-189$ & 0.74 & 0.80 \\
UDO99-043 & 13 & $177-223$ & 0.95 & 0.93
\end{tabular}

${ }^{\mathrm{z}}$ Duplicated locus.

from one tree per cultivar. All cultivars had been described previously and identified by standard morphological descriptors (Barranco et al., 2000).

DNA isolation and amplification. Total genomic DNA for simple-sequence-repeat(SSR) analysis was isolated from fresh leaf material following the procedure of Belaj et al. (2001). SSR assays were performed as described by Cipriani et al. (2002) using 9 primers from the 30 primer set described by these authors. They were UDO99-008, UDO99-009, UDO99011, UDO99-014, UDO99-019, UDO99-024, UDO99-031, UDO99-039, and UDO99-043. One of the primer was labelled with $\gamma-\left[{ }^{33} \mathrm{P}\right]-$ ATP and PCR products were separated on $6 \%$ denaturing polyacrylamide gel (Long Ranger, FMC BioProducts) containing $7 \mathrm{~m}$ urea and run with $1.2 \times$ TBE buffer at a constant power of $55 \mathrm{~W}$. The gels were then dried and autoradiographed on X-ray film using standard procedures. A reference molecular size marker was prepared from pUC18 plasmid DNA, that was sequenced using the M13 universal primer (Amersham Pharmacia Biotech AB, Sweden), radioactively labelled as above, and the four sequencing reactions were loaded onto the gel. Allele scoring and sizing was done visually using the plasmid sequence lanes as a length reference. We used 'Frantoio', from which the microsatellites had been originally isolated and sequenced as a reference in all gels, as recommended by Cipriani et al. (2002). All PCR reactions and electrophoreses were repeated at least twice and each gel was scored independently by three people.

Data analysis. The information content of microsatellite loci was estimated either by gene diversity or heterozygosity $(\mathrm{H})(\mathrm{Nei}, 1973)$ according to the formula $\mathrm{H}=1-\Sigma \mathrm{p}_{\mathrm{i}}^{2}$, where $p_{i}$ is the frequency of the $i^{\text {th }}$ allele and by the power of discrimination (PD) (Kloosterman et al., 1993), according to the formula as above, where the allele frequency was replaced by the genotype frequency. The first index is an estimation of the probability that two alleles of any locus chosen at random from the population of study are different, and heterozygosity averaged over all loci provides a measure of genetic diversity of the population of study. The discrimination power at a given locus provides an estimate of the probability that two randomly sampled accessions in the study are differentiated by their allelic profile at that locus. Cultivars showing only one fragment amplified by a pair of primers were conventionally considered to be homozygous at that locus. As a consequence, the heterozygosity reported here could be underestimated, if null alleles occurred.

Dice's coefficient (Dice, 1945) was used and the cultivars were grouped by cluster analysis using the unweighted pair-group method (UPGMA). The computer program used was NTSYS-pc version 2.02 (Rohlf 1998). The cophenetic correlation coefficient was calculated and Mantel's test (Mantel, 1967) was performed to check the goodness of fit of a cluster analysis to the matrix on which it was based.

\section{Results and Discussion}

The nine SSRs primers produced polymorphic amplification products in the cultivars studied. Three out of eight primer pairs (UDO99-009, UDO99-011, and UDO99-043) generated multiple bands, possibly because of the amplification at the same time of two different loci (Table 2). High frequency of microsatellites amplifying multiple locus has also been reported in olive by Rallo et al. (2000). This phenomenon is relatively common in species of allopolyploid origin, although this has not been clearly demonstrated in olive (Minelli et al., 2000) and may be due to genome fusion and chromosome duplication events during evolution (Buteler et al., 1999).

The total number of alleles amplified by the 9 primer pairs was 68 . The number of alleles per locus was 7.5 on average, ranging from a minimum of 5 for UDO99-008 and UDO99-019 to a maximum of 13 for the most polymorphic marker, UDO99-043 (Table 2). High levels of polymorphism and high number of alleles were expected for olive micosatellites markers. Rallo et al. (2000) found 3 to 9

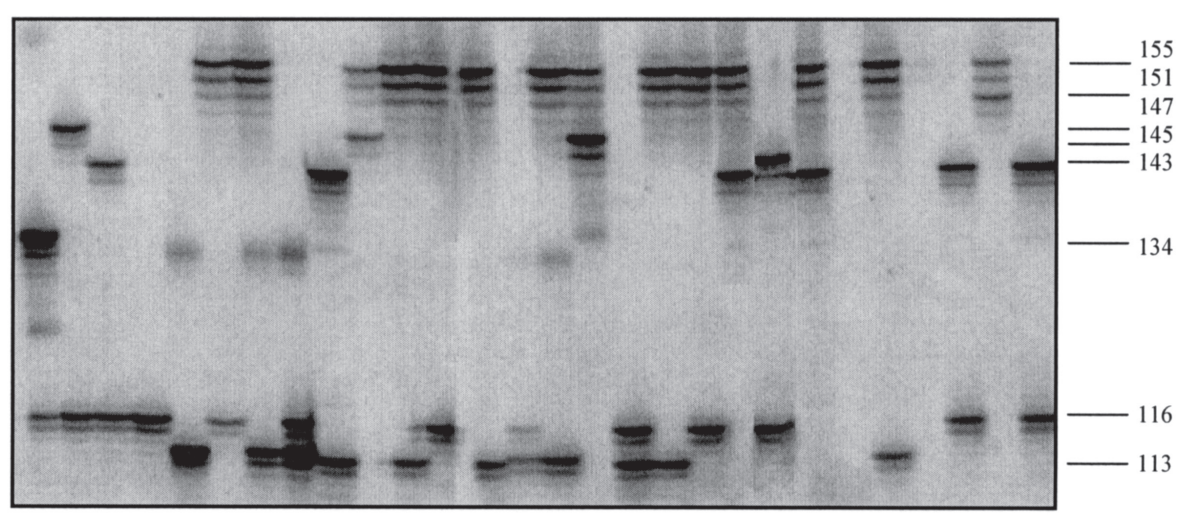

Fig..1 Autoradiogram of PCR amplified microsatellite UDO99-031. Alleles and their respective sizes (bp) are marked on the right side of the photo. alleles per locus in a set of 46 cultivars. Sefc et al. (2000) used 15 microsatellites primers in 47 Iberian and Italian trees revealing 4 to 15 alleles per locus. The average number of alleles per locus recorded in the present study was higher than the one reported by Cipriani et al. (2002) with the same primers. This could be explained by the low number of cultivars used and/or by coancestry of the cultivars of that study. High variability of Spanish and Italian olive germplasm have also been observed by means of morphological descriptors (Barranco et al., 2000), isoenzymes (Trujillo et al., 1995), and other molecular markers such as randomly amplified polymorphic DNA (RAPD) (Belaj et al., 2001; Fabbri et al., 1995; Sanz-Cortés et al., 2001; Vergari et al., 1996), and amplified fragment-length polymorphisms (AFLPs) (Baldoni et al., 2000).

Figure 1 represents an example of cultivar profile at one microsatellite loci. Allele scoring was reliable in almost all cases, in spite of the band stuttering, typical of this kind of markers (Testolin et al., 2000). The frequency for each allele ranged from 0.015 to 0.92 (data not shown) and was generally low, with many alleles detected in only one or two cultivars. Twelve cultivars $(34.3 \%)$ contributed most to the rare (unique) alleles (Table 3 ).

Both indexes of genetic variation, that is, the heterozygosity and the power of discrimination were high. Because of the negligible presence of null alleles, the heterozygosity reported here can be considered as a correct representation of the heterozygosity of the olive sample. The lack of amplification products for some cultivars, such as 'Leccino' and 'Leccio del Corno', could be attributed to the poor DNA quality of those samples. The same cultivars have also presented amplification problems with RAPD markers (Belaj, unpublished data). The gene diversity or heterozigosity ranged from 0.15 to 0.95 . This index was not calculated for the three duplicated loci because the number of alleles per locus was not ascertainable although each amplification product (allele) was identified easily. The power of discrimination followed, as expected, the gene diversity, ranging from 0.30 to 0.93 with a mean value of 0.79 . The two indexes varied almost irrespectively of the number of alleles, because the presence of many rare or less frequent alleles has little 
Table 3. Characterization of 35 olive cultivars using 9 SSR primer pairs. The number of different genotype profiles and the cultivars distinguished by each primer either by unique allelic patterns (in bold) or by unique alleles (in bold*) are also reported.

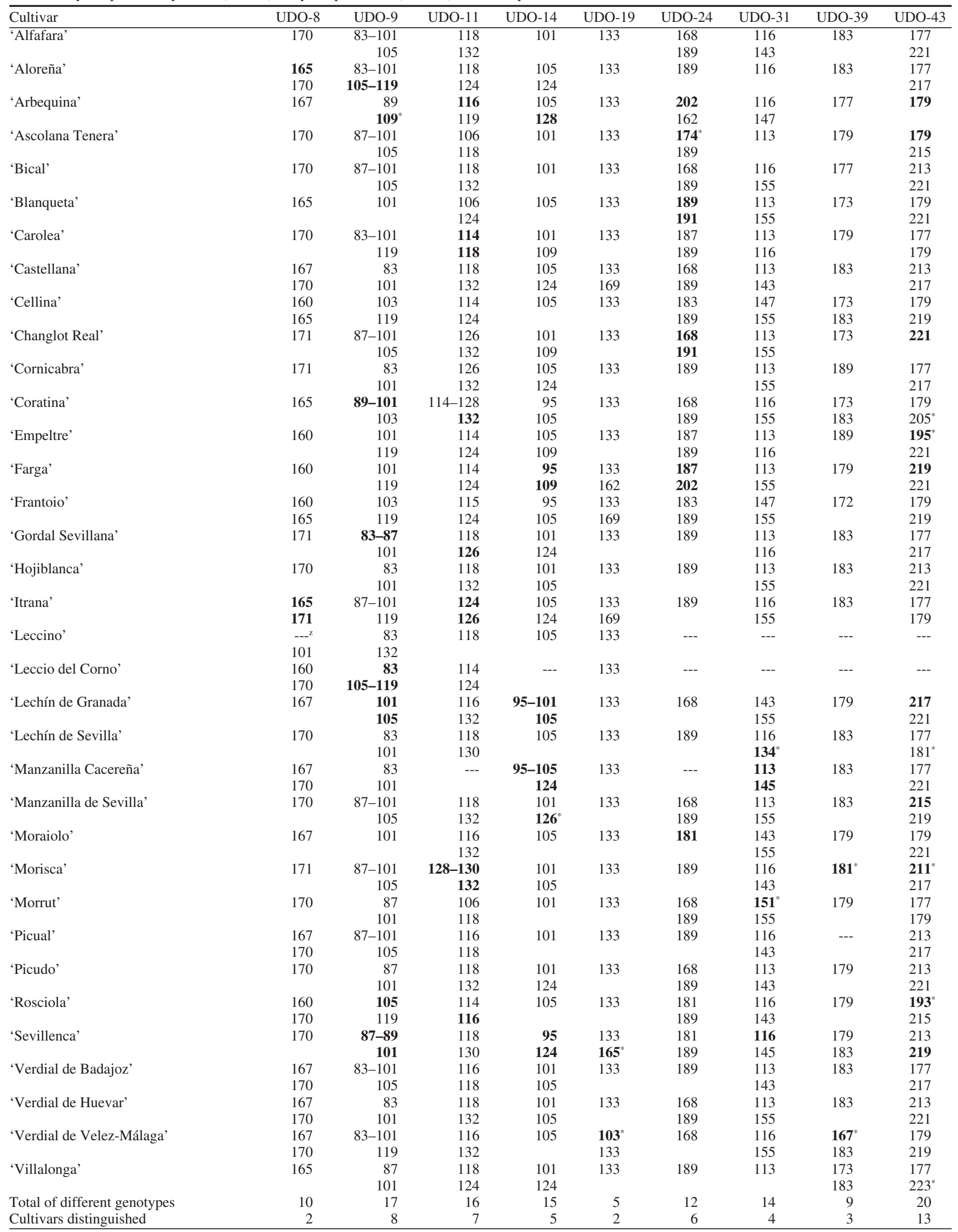

${ }^{2}$ Missing data. 

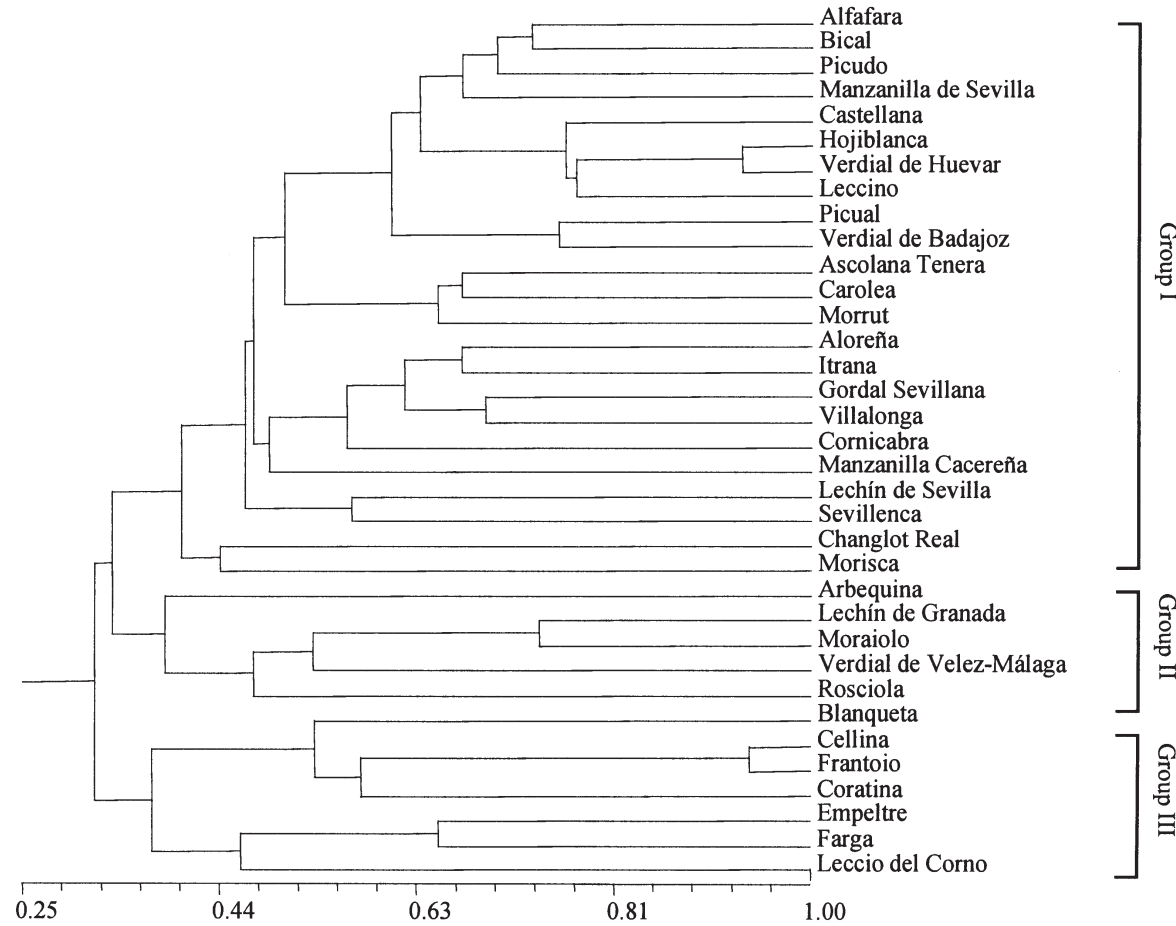

Fig. 2. Dendrogram of Italian and Spanish cultivars based on Dice coefficient and UPGMA cluster analysis.

influence on each of the indices values. The high discriminatory power of the microsatellite loci examined in olive is comparable with that reported for other fruit species such as apple (Hokanson et al., 2001), grape (Sefc et al., 1998), and peach (Testolin et al., 2000).

As a consequence of the high variability found, all varieties were easily discriminated from each other. In total, 118 different genotype profiles were obtained with the 9 loci, 50 of them being unique genotype profiles (Table 3). The microsatellite locus UDO99-43 revealed the highest number of polymorphisms allowing 13 different genotypes to be identified. The combination of the allelic patterns obtained by three primer pairs-UDO99-09, UDO99-43, and UDO99-14-made possible the identification of all cultivars included in the study. Seventeen cultivars $(48.5 \%$ of the genotypes included in the study) presented unique genotype patterns for these primer pairs. The combination of five loci made possible the identification of the $95 \%$ of the olive cultivars analysed (46) in the study carried out by Rallo et al., (2000). However, 'Hojiblanca' and 'Leccino' could not be distinguished from each other in that study.

A relatively high range of similarity values among genotypes (data not shown) was observed. The greatest similarity $(0.93)$ was observed between 'Hojiblanca' and 'Verdial de Huevar'. The lowest similarity values (0.13) were obtained between 'Frantoio' and 'Gordal Sevillano'. The cophenetic correlation coefficient between the dendrogram and the original distance matrix was significant but not very high $(r=0.73 ; p<0.01)$.

In the dendrogram (Fig. 2), most of the cultivars could be classified into three groups.

Of the 23 cultivars included in Group I,
14 were from Spain $(73 \%$ from southwestern and central) and only 4 ('Leccino', 'Ascolana Tenera', 'Carolea', and 'Itrana') were from from Italy. Five cultivars, 'Alfafara', 'Morrut', 'Villalonga' 'Sevillenca' and 'Changlot Real' come from eastern Spain.

Group II was formed by 'Arbequina' from eastern Spain, two Italian cultivars 'Moraiolo' and 'Rosciola' (both from central Italy), and 'Lechín de Granada' and 'Verdial de VelezMálaga', both from southern Spain.

Group III consisted of seven cultivars, four of which come from southwestern and central Italy ('Cellina', 'Coratina' 'Frantoio', and 'Leccio del Corno') and the rest ('Blanqueta', 'Empeltre' and 'Farga') came from northeastern Spain.

No differentiation between Spanish and Italian cultivars was found, but most of the cultivars from southern and central Spain clustered together. This structure of the genetic diversity most likely reflects a process of multilocal selection in olive (Besnard et al., 2001), a limited diffusion of olive cultivars out of their areas of cultivation (Sanz-Cortés et al., 2001), and a possible exchange of plant material among the different regions and countries along the history of olive cultivation (Angiolillo et al., 1999). The clustering together of cultivars from southern and central Spain has also been observed with isozymes (Trujillo, personal communication) and RAPDs (Belaj et al., 2001).

Our results support the utility of SSR markers in identification and diversity studies in olive. The identification of cultivars is one of the major applications of microstellite markers in olive. Therefore, the potential of the markers to yield different genotypes for as many cultivars as possible is of great interest, and selection of the most informative markers reduces the number of loci to be investigated for reliable cultivar distinction. SSR-based fingerprinting of olive cultivars may help generate a molecular database that will facilitate management of cultivar collections, trade control of plant material, and selection of genotypes for breeding programs. For such a purpose, further studies with larger olive samples are needed in the future.

\section{Literature Cited}

Angiolillo, A., M. Mencuccini, and L. Baldoni. 1999. Olive genetic diversity assessed using amplified fragment length polymorphisms. Theor. Appl. Genet. 98:411-421.

Baldoni, L., M. Pellegrini, M. Mencuccini, A. Angiolillo, and M. Mulas. 2000. Genetic relationships among cultivated and wild olives revealed by AFLP markers. Acta Hort. 521:275-284.

Barranco, D. 1997. Variedades y patrones, p. 59-80. In: D. Barranco, R. Fernández-Escobar, and L. Rallo (eds.). El cultivo del olivo. Mundiprensa y Junta de Andalucía, Madrid, Spain.

Barranco, D. and L. Rallo. 1984. Las variedades de olivo cultivadas en Andalucía. M. ${ }^{\circ}$ de Agricultura, Junta de Andalucía, Madrid, Spain.

Barranco, D., A. Cimato, P. Fiorino, L. Rallo, A Touzani, C. Castañeda, F. Serafíni, and I. Trujillo. 2000. World catalogue of olive varieties. Intl. Olive Oil Council, Madrid, Spain.

Bartolini, G., G. Prevost, C. Messeri, and G. Carignani. 1998. Olive germplasm: Cultivars and world-wide collections. Food Agr. Org., Rome.

Belaj A., I. Trujillo, R. de la Rosa, L. Rallo, and M.J. Giménez. 2001. Polymorphism and discriminating capacity of randomly amplified polymorphic markers in an olive germplasm bank. J. Amer. Soc. Hort. Sci. 126:64-71.

Besnard, G., P. Baradat, and A. Bervillé. 2001. Genetic relationships in the olive (Olea europaea L.) reflect multilocal selection of cultivars. Theor. Appl. Genet. 102:251-258.

Buteler, M.I., R.L. Jarret, and D.R. LaBonte. 1999. Sequence characterization of microsatellites in diploid and poliploid Ipomoea. Theor. Appl. Genet. 99:123-132.

Cantini, C., A. Cimato, and G. Sani. 1999. Morphological evaluation of olive germplasm present in Tuscany region. Euphytica 109:173-181.

Carriero, F., G. Fontanazza, F. Cellini, and G. Glorio. 2002. Identification of simple sequence repeats (SSRs) in olive (Olea europaea L.). Theor. Appl. Genet. 104:301-307.

Cimato, A., C. Cantini, G. Sani, and M. Marranci. 1993. Il germoplasma dell'Olivo in Toscana. Ed. Regione Toscana, Florence, Italy.

Cipriani, G., M.T. Marrazzo, R. Marconi, A. Cimato, and R. Testolin. 2002. Microsatellite markers isolated in olive are suitable for individual fingerprinting and reveal polymorphism within ancient cultivars (Olea europaea L.). Theor. Appl. Genet. 104:223-228.

De la Rosa, R., C. James, and K.R. Tobutt. 2002. Isolation and characterization of polymorphic microsatellite in olive (Olea europaea L.) and their transferability to other genera in the Oleacea. Primer note. Mol. Ecol. (in press).

Dice, L.R. 1945. Measures of the amount of ecologic association between species. Ecology 26:297-302.

Fabbri, A., J.I. Hormaza, and V.S. Polito. 1995. Random amplified polymorphic DNA analysis of olive (Olea europaea L.) cultivars. J. Amer. Soc. Hort. Sci. 120:538-542.

Hokanson, S. C., W.F. Lamboy, A.K. Szewc-Mc- 
Fadden, and J.R. McFerson. 2001. Microsatellite (SSR) variation in a collection of Malus (apple) species and hybrids. Euphytica 118:281-294.

Kloosterman, A. D., B. Budowle, and P. Daselaar. 1993. PCR amplification and detection of the human D1S80 VNTR locus. Amplification conditions, population genetics and application in forensic analysis. Intl. J. Leg. Med. 105:257-264.

Mantel, N. 1967. The detection of disease clustering and a generalized regression approach. Cancer Res. 27: 209-220.

Mekuria, G.T., G.G. Collins, and M. Sedgley. 1999. Genetic variability between different accessions of some common commercial olive cultivars. J. Hort. Sci. Biotechnol. 74:309-314.

Minelli, S., F. Maggini, M.T. Gelati, A. Angiolillo, and P.G. Cionini. 2000. The chromosome complement of Olea europaea L.: Characterization by differential staining of the chromatin and in situ hybridization of highly repeated DNA sequences. Chrom. Res. 8:615-619.

Nei, M. 1973. Analysis of gene diversity in subdivided populations. Proc. Natl. Acad. Sci. USA 70:3321-3323.
Patumi, M., G. Fontanazza, R. Nucci, and C. Vaccaro. 1994. Preliminary studies on isoenzymatic and enzymatic activities isolated from olive plant. Acta Hort. 356:95-97.

Prevost, G., G. Bartolini, and C. Messeri. 1993. Italian olive cultivars and their synonyms. Menegazzo ed., Lucca. Italy.

Rafalski, J.A., J.M. Vogel, M. Morgante, W. Powell, C. Andre, and S.V. Tingey. 1996. Generating and using DNA markers in plants, p. 75-134. In: In: B. Birren and E. Lai (eds.). Nonmammalian genomic analysis. A practical guide. Academic Press, San Diego,

Rallo, P., G. Dorado, and A. Martin. 2000. Development of simple sequence repeats (SSRs) in olive tree (Olea europaea L.). Theor. Appl. Genet. 101:984-89.

Rohlf, F.J. 1998. NTSYS-pc. numerical taxonomy and multivariate analysis system. version 2.00. Exeter Software, Setauket, N.Y.

Sefc, K.M., F. Regner, J. Glössl, and H. Steinkellner. 1998. Genotyping of grapevine and rootstock cultivars using microsatellite markers. Vitis 37:15-20.

Sefc, K. M., M.S. Lopes, D. Mendonça, M. Rodrigues
Dos Santos, M. Laimer Da Câmara Machado, and A. Da Câmara Machado. 2000. Identification of microsatellite loci in olive (Olea europaea) and their characterization in Italian and Iberian olive trees. Mol. Ecol. 9:1171-1173.

Testolin, R., T. Marrazzo, G. Cipriani, R. Quarta, I. Verde, M.T. Dettori, M. Pancaldi, and S. Sansavini. 2000. Microsatellite DNA in peach (Prunus persica $\mathrm{L}$. Batsch) and its use in fingerprinting and testing the genetic origin of cultivars. Genome 43:512-520.

Tous, J. and A. Romero. 1993. Variedades del Olivo. Fundación "La Caixa", Barcelona, Spain.

Trujillo, I., L. Rallo, and P. Arus. 1995. Identifying olive cultivars by isozyme analysis. J. Amer. Soc. Hort. Sci. 120:318-324.

Vergari, G., M. Patumi, and G. Fontanazza. 1996. Use of RAPD markers in the characterisation of olive germplasm. Olivae 60:19-22.

Wiesman, Z., N. Avidan, S. Lavee, and B. Quebedeaux. 1998. Molecular characterization of common olive varieties in Israel and the West bank using randomly amplified polymorphic DNA (RAPD) markers. J. Amer. Soc. Hort. Sci. 123:837-841. 